\title{
Morphological Study of the Coronoid Process of Mandible in North Indian Population
}

\author{
Anamika Gaharwar ${ }^{1}$, Vineeta Tewari ${ }^{2}$ \\ ${ }^{1}$ Assistant Professor, Department of Anatomy, Ram Manohar Lohia Institute of Medical Sciences, Gomtinagar, Lucknow, ${ }^{2}$ Professor, Department of \\ Anatomy, ELMCH, Lucknow.
}

\section{Abstract}

Introduction: Morphological variations in coronoid process are produced by the corresponding developmental variations. The present study was conducted to assess morphological variations of coronoid process of mandible. Subjects and Methods: The present study was conducted in the department of Anatomy. It comprised of 100 subjects of both genders. All subjects were subjected to panoramic radiograph. The different shapes of coronoid process were compared. Results: Out of 100 subjects males were 50 and females were 50 . Triangular shape coronoid process was seen in 32 males and 36 females, hook shaped in 14 males and 8 females and rounded shaped in 4 males and 6 females. The difference was non- significant ( $\mathrm{P}>0.05)$. On left side triangular shape was seen in 33 and 35 on right side, hook form was seen in 10 in left side and 7 in right side and rounded was seen 7 in left side and 8 in right side. The difference was nonsignificant $(\mathrm{P}>0.05)$. Conclusion: Authors found variation in shape of coronoid process. Most common type was triangular followed by hook variety.

Keywords: Coronoid, Mandible, Morphological.

Corresponding Author: Dr. Vineeta Tewari, Professor, Department of Anatomy, ELMCH, Lucknow.

Received: May 2019

Accepted: June 2019

\section{Introduction}

Elongation of the coronoid process may be found bilaterally or unilaterally, resulting in progressive, painless restriction in mandibular opening, due to impingement of the coronoid on the medial aspect of the zygomatic arches. This rare condition is more common in males, etiology of which is unknown. ${ }^{[1]}$

The common treatment involves the sectioning of the coronoid process. The coronoid process is ossified from membrane, it also shows less resorption. Autogenous bone grafts can be obtained from ilium, rib and calvarias; but each site has its own associated morbidity. ${ }^{[2]}$

Morphological variations are produced by the corresponding developmental variations through hereditary determinants and the functional changes that take place during the growth process. The muscle and bone may dynamically affect the function of each other and lead to the changes in the morphology of the bone involved. ${ }^{[3]}$

A local bone graft from coronoid process of mandible can be used as it can be harvested easily, minimal morbidity, shorter surgical and hospitalization time, no cutaneous scarring as bone is harvested intraorally. A Coronoid process graft can be used for alveolar defects repair, orbital floor repair, maxillary augmentation, repair of non-union fracture of mandible. ${ }^{[4]}$ The present study was conducted to assess morphological variations in coronoid process of mandible in north Indian population.

\section{Subjects and Methods}

The present study was conducted in the Department of Anatomy, GSVM, Kanpur. It comprised of 100 subjects of both genders. The sex of the mandible was determined according to the following criteria.

\begin{tabular}{|l|l|l|}
\hline Criteria & Males & Females \\
\hline Angle & Everted & Less everted \\
\hline Muscular impressions & More prominent & Less prominent \\
\hline Chin & Square & Round \\
\hline Size & Large & Small \\
\hline
\end{tabular}

The age of the mandible was determined according to the following criteria:

\begin{tabular}{|l|l|l|}
\hline Criteria & Adult & old \\
\hline Alveolar arch & Well formed & Resorbed \\
\hline $\begin{array}{l}\text { Position of Mental } \\
\text { Foramen }\end{array}$ & $\begin{array}{l}\text { Between upper \& } \\
\text { lower borders of } \\
\text { mandible }\end{array}$ & $\begin{array}{l}\text { Towards the upper } \\
\text { border of mandible }\end{array}$ \\
\hline
\end{tabular}

The different shapes of the coronoid process were compared. The results thus obtained were subjected to statistical analysis.

General information such as name, age, gender etc. was 
recorded. All subjects were subjected to panoramic radiograph. The different shapes of coronoid process were compared. Results thus obtained were subjected to statistical analysis. $\mathrm{P}$ value less than 0.05 was considered significant.

\section{Results}

Table 1: Distribution of subjects
\begin{tabular}{|l|l|l|}
\hline Total- 100 & Females \\
\hline Gender & Males & 50 \\
\hline Number & 50 & 5 \\
\hline
\end{tabular}

[Table $1 \&$ Graph 1] shows that out of 100 subjects males were 50 and females were 50 .

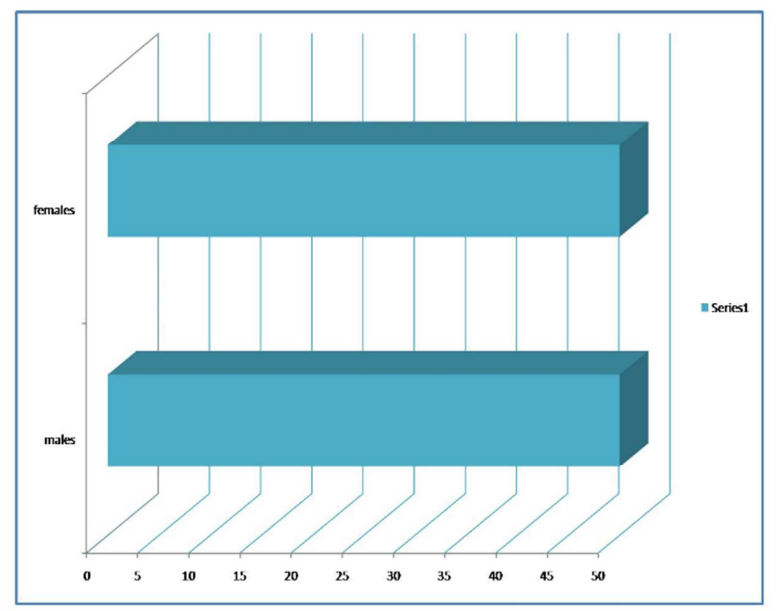

Table 2: Age distribution of subjects

\section{Total- 100}

\begin{tabular}{|l|l|l|}
\hline Age & Adult & Old \\
\hline Number & 32 & 68 \\
\hline
\end{tabular}

[Table 2 \& Graph 2] shows that out of 100 subjects Adults were 32 and Old were 68.

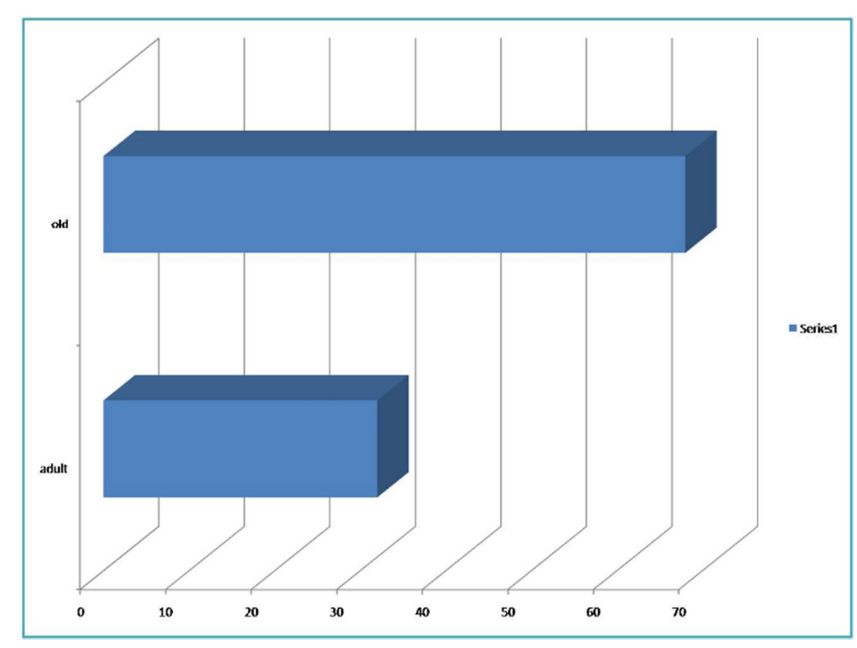

Table 3: Morphological Variation of Coronoid process with

Gender

\begin{tabular}{|l|l|l|l|}
\hline Shape & Male & Female & P value \\
\hline Triangular & 32 & 36 & 0.51 \\
\hline Hook & 14 & 8 & 0.12 \\
\hline Rounded & 4 & 6 & 0.72 \\
\hline
\end{tabular}

[Table $3 \&$ Graph 3] shows that out of 50 males 32 had triangular, 14 had Hooked, and 4 had Rounded coronoid process. And out of total 50 Females 36 had triangular, 8 had Hooked, and 6 had Rounded coronoid process.

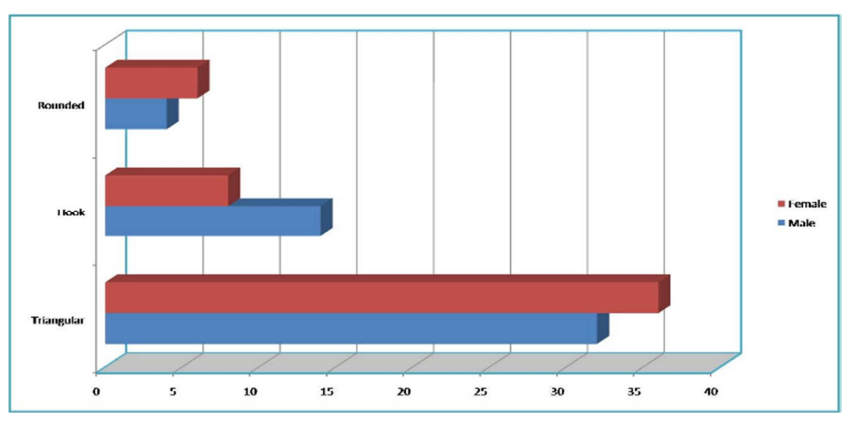

Table 4: Morphological Variation of Coronoid process with Age

\begin{tabular}{|l|l|l|l|l|}
\hline Shape & Adult & Percentage & Old & Percentage \\
\hline Triangular & $21 / 32$ & $65.62 \%$ & $41 / 68$ & $60.29 \%$ \\
\hline Hook & $8 / 32$ & $25.00 \%$ & $20 / 68$ & $29.41 \%$ \\
\hline Rounded & $3 / 32$ & $9.375 \%$ & $7 / 68$ & $10.29 \%$ \\
\hline
\end{tabular}

[Table 4 \& Graph 4a, 4b] shows that out of 32 Adults 21 had triangular i.e. $65.62 \%, 8$ had Hookedi.e $25.00 \%$, and 3i.e. $9.375 \%$ had Rounded coronoid process. And out of 68 old 41 i.e. $60.29 \%$ had triangular, 20 i.e $29.41 \%$ had Hooked, and 7 i.e. $10.29 \%$ had Rounded coronoid process.

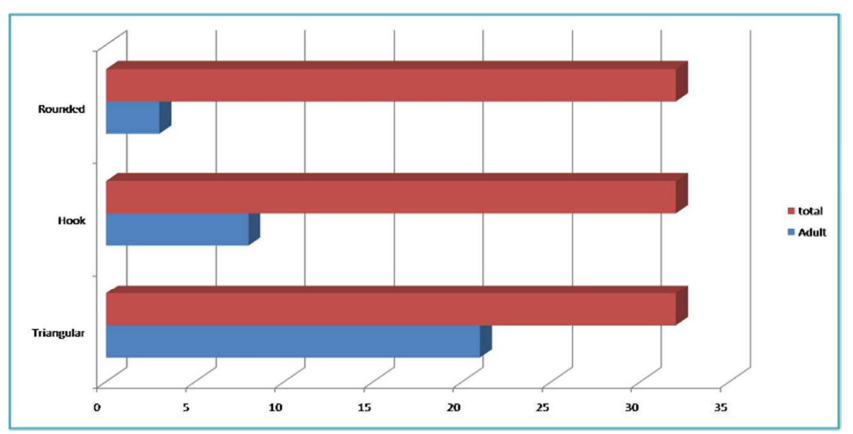

Graph 4a

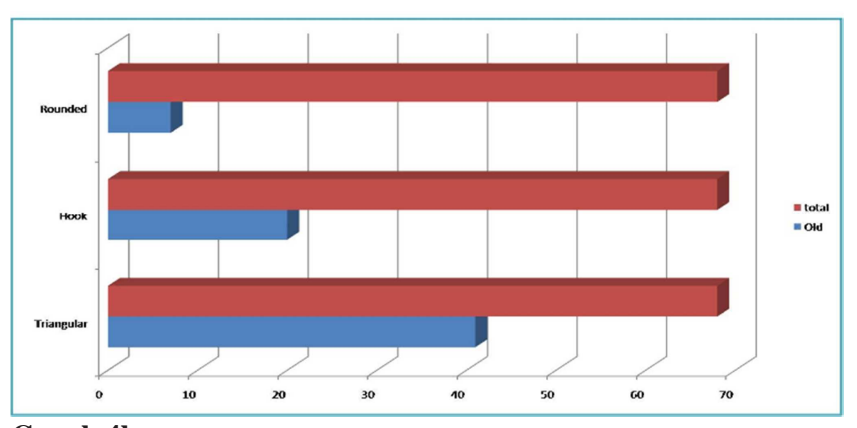

Graph 4b 
Table 5: Morphological Variation of Coronoid process with

Side

\begin{tabular}{|l|l|l|l|}
\hline Shape & Left side & Right side & P value \\
\hline Triangular & 33 & 35 & 0.5 \\
\hline Hook & 10 & 7 & 0.2 \\
\hline Rounded & 7 & 8 & 0.1 \\
\hline
\end{tabular}

[Table 5 \& Graph 5] shows that out of 50 left sided mandible 33 had triangular, 10 had Hooked, and 7 had Rounded coronoid process. And out of total 50 right sided mandible 35 had triangular, 7 had Hooked, and 8 had Rounded coronoid process
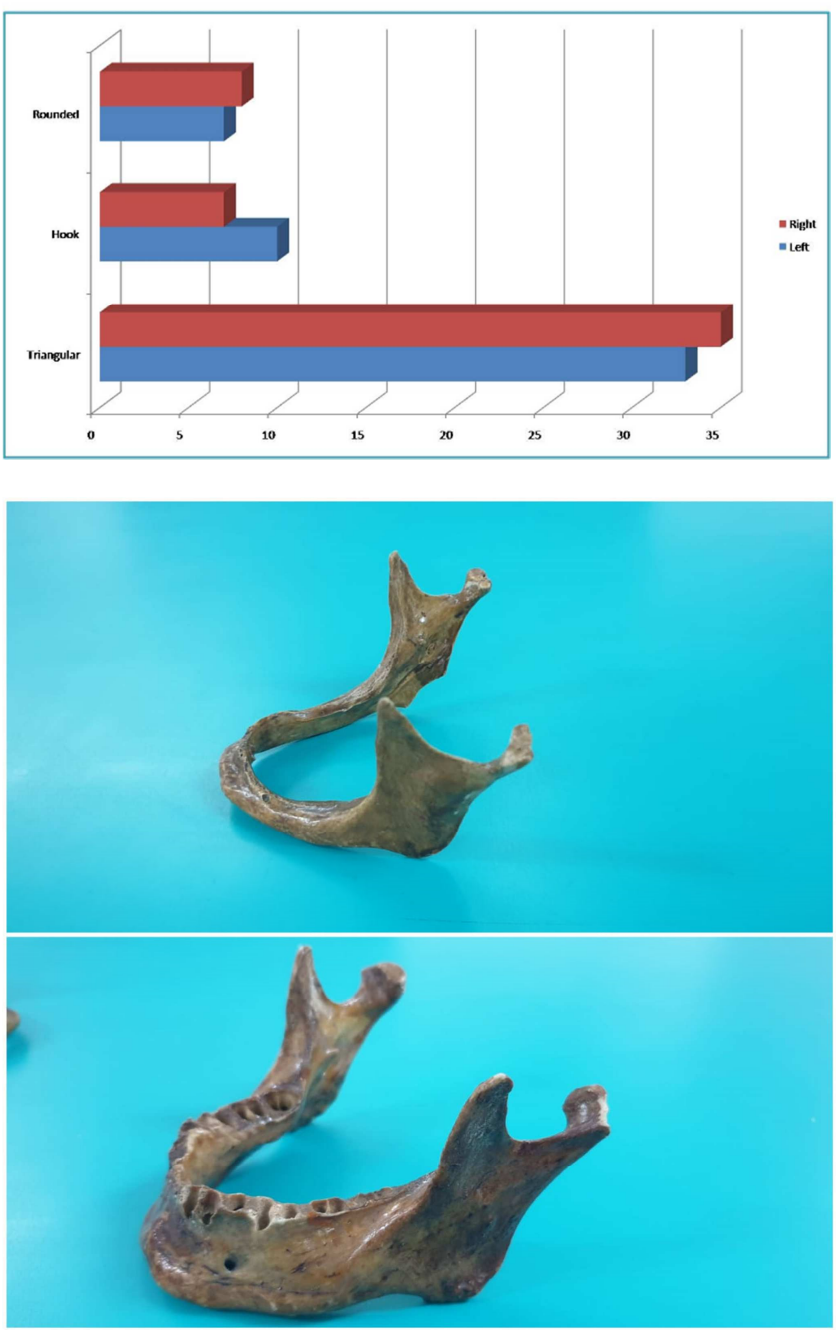

Figure 1: Old aged and adult aged mandibles.

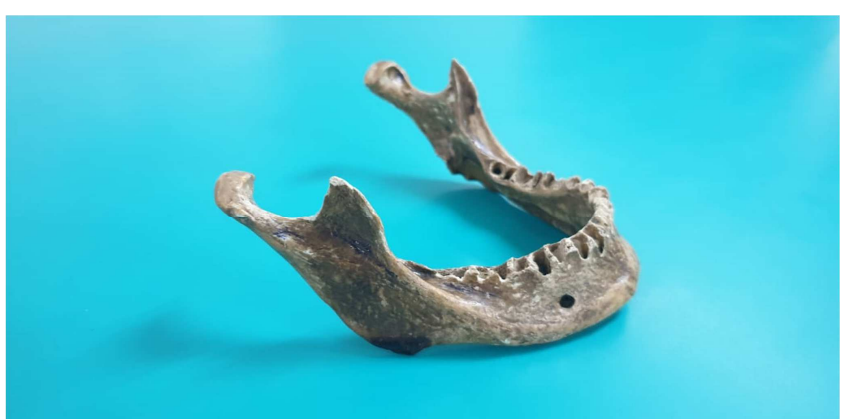

Figure 2: Rounded coronoid process

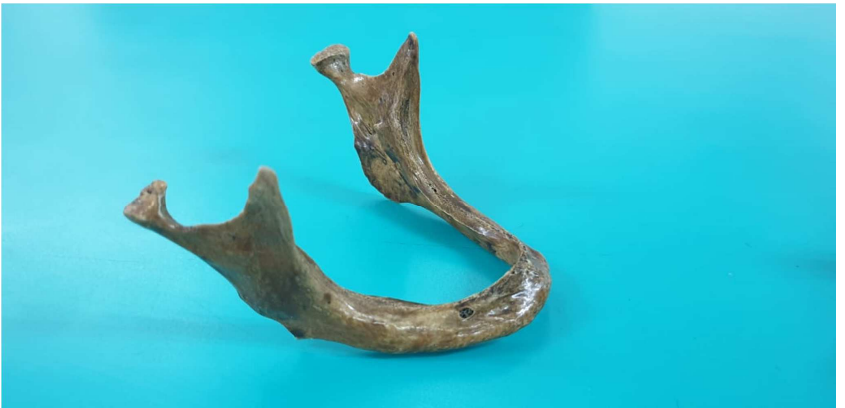

Figure 3: Triangular coronoid process

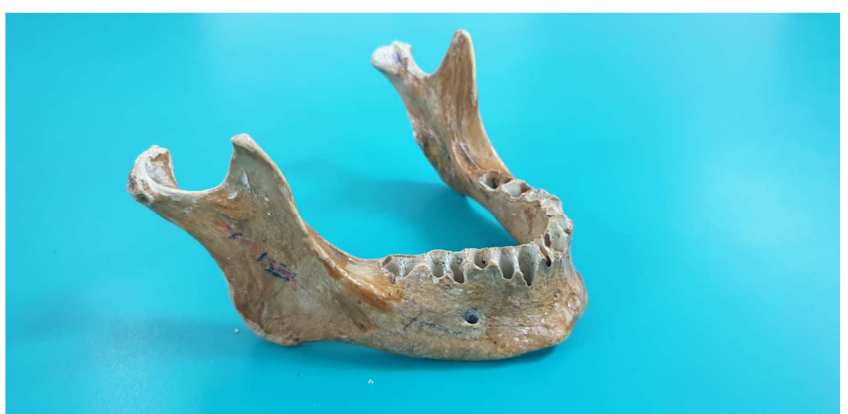

Figure 4: Hooked coronoid process

\section{Discussion}

Literature search suggest varying form of coronoid process in adult human mandibles. Early back in 1915 Schaffer called it beak shaped process. Sable like curvature of the process was interpreted as a manifestation of ageing. ${ }^{[5]}$ The coronoid process of the mandible is gaining vital importance as a graft material in all aspects of reconstructive craniomaxillofacial surgeries like orbital floor reconstruction, paranasal augmentation, temporomandibular joint ankylosis, etc. Coronoid process is also being used as a non metric skull variant in assessment of age, sex, race and species. ${ }^{[8]}$ The clinical and other applications of coronoid morphology are in the field of reconstructive surgery and anthropology has been well documented in literature. However except for a few paper presentations no detailed account about coronoid morphology has been cited so far. ${ }^{[6]}$ The present study was conducted to assess morphological study of coronoid process of mandible.

In present study, triangular shape coronoid process was seen in 32 males and 36 females, hook shaped in 14 males and 8 females and rounded shaped in 4 males and 6 females. Shakya et al, ${ }^{[7]}$ in their study the morphological analysis of shapes of coronoid process of both side of fifty dry adult human mandibles of Indian origin (100 sides) were done in order to classify the variations. Three types of variations in the shape were evident. Triangular, hook shaped and rounded. Triangular shaped coronoid process was found in $60(60 \%)$ sides, hook shaped process in $22(22 \%)$ and round shaped in $18(18 \%)$ sides.

We observed that on left side triangular shape was seen in 33 and 35 on right side, hook form was seen in 10 in left side and 7 in right side and rounded was seen 7 in left side and 8 in right side. Prajapati et al,$^{[8]}$ in their study, the various presentations of coronoid process were observed and broadly classified, on both the sides. Hook shaped coronoid 


\section{Gaharwar d I ewari; Marphalagical Study of the Caranaid Pracess of Mandile}

process was the most predominant type $(61.5 \%)$ followed by triangular $(14 \%)$ and rounded $(12.5 \%)$ types. About $12 \%$ belonged to the miscellaneous type. Hook shape coronoid process was significantly higher in the females. The other shapes did not show any significant gender variation. It was inferred that the structural changes at the coronoid process of mandible help oneself to distinguish the gender of the individual.

It is documented that diet has a vital role in affecting the muscular pull on the bony process and as such can alter the shape of coronoid process markedly. Occupation and hormonal effect also has its effect (e.g. basket makers, who often use their mouth for weaving, tend to have a bigger coronoid process due to functional over activity of the temporalis). ${ }^{[9]}$

\section{Conclusion}

Authors found variation in shape of coronoid process. Most common type was triangular followed by hook variety.

\section{References}

1. H., O. Kansu, F. Akgunlu. Bifid coronoid process. Oral surgery, Oral Medicine, Oral Pathology 1994; 78(2): 136.

2. Ranganath, P., Manjunath K.Y., Balasubramanya. The varying shape of coronoid process of the mandible. Indian Journal of Dental Research 2004; 15(3): 96-98.

3. Meopi N Syropoulos; The morphogenetic relationship of the temporalis muscle to the coronoid process in human embryos and fetuses. American Journal of Anatomy 1977; 150:395-410.

4. Isaac B, Holla SJ. Variations in the Shape of the Coronoid Process in the Adult Human Mandible. J Anat. Soc. India. 2001; 50(2): 137-139.

5. Khan TA., Sharieff JH. Observation on Morphological Features of Human Mandibles in 200 South Indian Subjects. Anatomica Karnataka. 2011; 5(1): 44-49

6. Nirmale VK, Mane UW, Sukre SB, Diwan CV. Morphological Features of Human Mandible. Int $\mathrm{J}$ of Recent Trends in Sci Technol. 2012; 3 (2): 38-43.

7. Shakya S, Ongole R, Nagraj SK. Morphology of Coronoid Process and Sigmoid Notch in Orthopantomograms in South Indian Population. World J Dent. 2013; 4:1-3.

8. Prajapati VP, Ojaswini Malukar O, Nagar SK. Variations in the Morphological Appearance of the Coronoid Process of Human Mandible. Nat J Med Res. 2011; 1: 64-66.

9. Pradhan, D. P. Bara, S. Patra, S. Nayak, C. Mohapatra. Anatomical Study of Various Shapes of Mandibular Coronoid Process in Relation to Gender \& age. Journal of Dental and Medical Sciences 2014; 13(8):09-14.

Copyright: $\odot$ the author(s), publisher. Academia Anatomica International is an Official Publication of "Society for Health Care \& Research Development". It is an open-access article distributed under the terms of the Creative Commons Attribution Non-Commercial License, which permits unrestricted non-commercial use, distribution, and reproduction in any medium, provided the original work is properly cited.

How to cite this article: Gaharwar A, Tewari V. Morphological Study of the Coronoid Process of Mandible in North Indian Population. Acad. Anat. Int. 2019;5(1):108-111.

DOI: dx.doi.org/10.21276/aanat.2019.5.1.26

Source of Support: Nil, Conflict of Interest: None declared. 